\title{
EMPLOYING MOODLE-SUPPORTED INSTRUCTION TO FOSTER GRAMMAR PERFORMANCE OF IRANIAN EFL LEARNERS
}

\author{
Armaghan Agha Abedi \\ M.A. Student of Translation, Islamic Azad University of Damavand, Iran \\ abediarmaghan@gmail.com
}

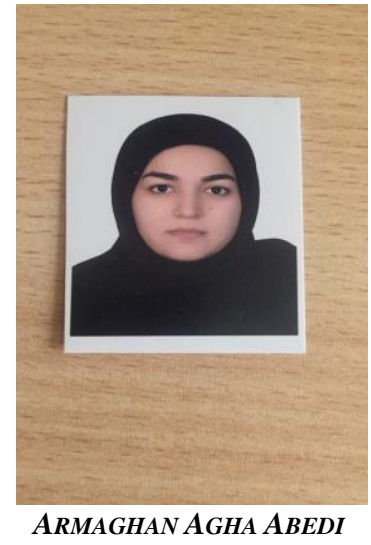

\begin{tabular}{lcc}
\hline $\begin{array}{l}\text { Keywords: } \\
\text { management }\end{array}$ & EFLs; $;$ & course \\
grammar & Moodle;
\end{tabular}

\begin{abstract}
A B S T R A C T
With the widespread popularity, of course management systems in educational contexts, a number of educators and practitioners have advocated the employment of such systems especially Moodle in the regular instruction. The purpose of the present paper was to investigate the effect of a Moodle-supported grammar instruction in the grammar performance of Iranian EFL students. In so doing, 51 Iranian EFL learners who were the students of two intermediate classes at a private language center in Tehran Province, Iran, were recruited as the participants of the study. One of the classes $(n=26)$ was randomly assigned as the experimental group and the other group $(n=25)$ was assigned as the control group. As the experimental intervention, specific grammar points supposed to be covered in the textbook were integrated into a Moodle system. The result of ANCOVA revealed that the experimental group students outperformed the control group on post-test of grammar. The findings indicate that Moodle-supported grammar instruction can foster the EFL students' grammar performance. Such findings suggest that electronic courses designed by means of the e-learning platform Moodle may be viable for the effective blended learning implementation in EFL courses.
\end{abstract}

Citation: Armaghan Agha Abedi (2018). M.A. Student of Translation, Islamic Azad University of Damavand, Iran. International Journal of Advanced Multidisciplinary Scientific Research (IJAMSR ) ISSN:2581-4281 Vol 1, Issue 3, May, 2018, \#Art.137, pp79-87 


\section{International Journal of}

\section{Introduction}

Over the past decade, education enterprise has witnessed a significant shift of attention and orientation, emphasizing a significant move toward a studentcentered and community-based modes of learning (Rovai \& Jordan, 2004). In line with such a significant shift, computers, internet and other technological devices and social networking websites have become an indispensable part of students' education and social life. This situation has led to the heightened interest in technology-mediated learning.

Technology-mediated learning is conceptualized as a kind of learning "delivered via any technology" (Anohina, 2005). From this perspective, Technology is considered as a resource from which any device can be selected for learning processes. Subscribing to this theoretical framework, educators and practitioners select various technological devices in order to enhance teaching and learning process. The adoption of technological devices has also affected the understanding and concept of what it means to teach and learn a language and how to change educational approaches compatible with the new changes (White, 2007). Given the significance of technology-mediated learning, some new terminologies have been introduced: distance language learning, online language learning, distributed language learning, virtual language learning, computer-assisted language learning, and web-based language learning (Anohina, 2005).

On the other hand, due to their intrinsic feature of availability and simplicity of the structure, new packages known as Learning Management Systems (LMSs) were created to facilitate learning in a variety of environments (Melton, 2006). Nevertheless, because of high fees, some LMSs, including WebCT and Blackboard, require a commercial support that language teachers cannot afford. To compensate for such inadequacies and shortcomings, Moodle (Modular object-oriented dynamic/developmental learning environment) was introduced as an open source LMS. Because of both the ubiquity of the internet and enhanced availability of network, this new package attracted the interest of many educators all over the world (Cole, 2005). The educators who employ Moodle can have access to a repertoire of powerful tools, including assignments, forums, journals, quizzes, surveys, chat rooms, and workshops (Cole, 2005).

\section{Blended learning}

Nowadays, it seems quite axiomatic that the Internet has significantly changed language teaching and language learning so that the current language methodologies should take into account the role of the Internet (Jarvis \& Krashen, 2014; Richards, 2015). As a result, today's foreign language teachers can no longer see themselves teaching without the Internet in the classroom. Over the last decade, numerous studies have examined the implementations of the Internet and online courses for foreign language teaching, especially at the tertiary level (Blake, 2008; Knutzen \& Kennedy, 2012). In order for an online course to be effective, the teacher must be equipped with the necessary skills and competencies of both e-learning and online teaching (Compton, 2009).

What is conceptualized as the blended learning is an integration of online learning and traditional face-toface, inside-the-class learning. However, it seems that there's no unanimity on how it is defined by numerous researchers. Dziuban, Hartman and Moskal (2004) maintain that blended learning should be considered as a pedagogical approach that integrates the effectiveness and socialization opportunities of the classroom with the technologically enhanced active learning possibilities of the online environment, rather than a ratio of delivery modalities. Blended learning is a departure from the lecture- to student-centered instruction in which students become active and interactive learners. It increases the interaction between student-instructor, student-student, student-content, and student-outside resources and it is also able to provide integrated formative and summative assessment mechanisms for students and teachers.

Kekang He (2004) thinks that the blended learning is a combination of the advantages of traditional way of learning and E-learning, which makes the instructors play the role of instruction, enlightenment and monitoring and fully embody students' initiatives, enthusiasm and creativity as the main stream of the learning process. His idea stresses the roles of instructors and students in the course of learning and teaching. 


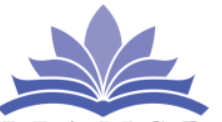

I J A M S R

\section{International Journal of}

Advanced Multidisciplinary Scientific Research (IJAMSR) ISSN:2581-4281

Jiahou $\mathrm{Li}$ (2007) defines blended learning as optimization selection and combination of all the teaching elements which aim to achieve the teaching aims. Li thinks the blended learning is supposed to require the instructors and students to apply various teaching methods, models, strategies, media and technologies skillfully in the course of teaching and learning, resulting in an artistic realm.

The blended learning is an optimal combination which aims to include the positive aspects of face-to-face learning and online learning. Students can have real experience of interaction on regular classes, while the online courses can supply the learners abundant resources, which can offer learners more flexibility and convenience to study.

Moreover, Blended learning courses in which a digital platform (e.g., Moodle) is combined with face-to-face foreign language courses can be effectively implemented by motivated, traditional teachers with little technological expertise, if the course has been duly designed by the course developer. In the literature, there is growing evidence acknowledging the positive role of such courses in enhancing the learning outcomes of the language learners (Sun, 2014; Tsai \& Talley, 2013; Tsai, 2014). One of the very recent digital platforms which can be applied in the EFL courses is the Moodle. One of the most widely used digital platforms, Moodle adds variety to teaching and brings about the diversification of teaching in innovative ways (Berns, Gonzalez-Pardo, \& Camacho, 2013).

\section{Moodle}

Moodle, a free learning management system, is an open source software for creating Internet-based lessons. This software brings about changes in the nature of the software business and this change is claimed to be especially effective in education. The access to open source software has affected both the method of using the software by educational centers, schools, learners, and teachers, and operating systems for educational purposes (Kamkarhaghighi et al, 2011).

From the theoretical point of view, Moodle is designed in line with social constructivism which emphasizes the role of interaction in learning. From this perspective, learning is more effective when the learners are involved with educational content, collaborate and cooperate with others, and communicate with other students about content and teaching materials (Rice, 2006).

Parallel with socio-communicative approaches within educational psychology, which highlight the role of social interaction, Moodle creates an environment for constructive interaction between the instructor and the learners. The main advantage of such an environment is the capability of adding some other features such as chat, forum, wiki, and glossaries to the course. Creating more interaction with the learning environment, Moodle is able to make courses more attractive and engaging in a sense that the learners become more enthusiastic to get involved in the course (Rice, 2006). Another intrinsic benefit of Moodle is that all learning activities of the virtual environment provide the possibility of giving qualitative and quantitative feedback, a feature that makes Moodle different from similar packages (Brandle, 2005).

Another alluring features of Moodle are the possibility to recording, storing, and archiving personal information of learners, administrators' access to educational databases, the ability to expand the system by adding the number of users, the possibility to support courses produced by manufacturers, assessment, testing and examining students and teachers, training resource management, close supervision on learner while presenting the content, test management, announcing the result, and suggesting the next stage of learning after lessons.

In a study conducted by Ayan (2015), Moodle's position as a device to motivate and create autonomous elearning in English language courses in Turkey was investigated. The participants of the study were the EFL learners who had not attended any English preparatory class at the university level and had never utilized a particular learning management system (LMS) to learn English before. The participants had four hours of English language classes per week in each term for a period of four years of their bachelor education. For the purpose of the study, the students made use of Moodle to learn and improve their English with asynchronous applications as an additional instruction to face-to-face sessions of the courses. At the end of almost four months 


\section{International Journal of}

of study, mean scores of their exam scores and a satisfaction scale were administered to evaluate the effectiveness of Moodle on students' motivations and autonomous learning. The findings of the study revealed that Moodle increased the levels of the students' motivation and autonomy to improve their English language skills.

In another study more relevant to the purpose of the present study, Bataineh and Mayyas (2017) examined the effect of Moodle-enhanced instruction on Jordanian EFL students' reading comprehension and grammar performance. The researchers employed a quasiexperimental, pre-/post-test design in which a sample of students in a language requirement course at a Jordanian state university was recruited and randomly divided into an experimental group and a control group. The experimental group was taught based on blended learning in which Moodle supplemented in-class instruction. The control group students were taught in a traditional, face-to-face mode. The statistical analysis of the data indicated that the experimental group outperformed the control group in terms of both reading comprehension and grammar.

\section{Moodle and learning communities}

In line with the prevailing acknowledgement and conceptualization of learning as an active and social activity, the concept of learning communities has become increasingly applied in educational systems at all levels. Put it simply, a learning community is a group of individuals who are involved in a variety of learning activities (Cross, 1998). Such learning communities have members bound together because of their commonalities in causes of learning, mutual support, and shared values and experiences (Jonassen, Peck, \& Wilson, 1999). The members of a learning community are committed to advance the collective knowledge of the

Community, and the members firmly believe that their educational needs can be met through participating in community-based activities (Rovai, 2002). A learning community provides the members with the opportunity for joint exploration and reflection of ideas, a mode of learning in a collaborative and supportive atmosphere (Palloff \& Pratt, 2007). Peer support and peer help are the other potentialities of a learning community, such a support can be manifested through instrumental help as well as emotional support (Bruckman, 2006).

Moodle as an open source Course Management System (CMS) that allows educators to build an online environment in support of teaching and learning activities has the potential to create a learning community in which the learners can also have online asynchronous discussions. From a pedagogical point of view, online asynchronous discussions have been acknowledged to be effective by several studies. Webbased discussions can enhance students' reflective ability and critical thinking skills (Barnett-Queen, Blair, \& Merrick, 2005; Burge, 1994; Chang, 2006; Whipp, 2003). Written communication in cyberspace provides the students with the opportunity students to take part in discussions at a more convenient time convenient and to articulate their ideas in more carefully planned and structured ways (Tiene, 2000). Unlike face-to-face interaction, online discussions allow the students to express their views or even disagreement freely and become more attuned to others' opinions (Barnett-Queen et al., 2005). Students' participation in online discussion contributes to improving their learning performance (Lin, and Huang, 2011).

In spite of its widespread use, there are few reliability, quality, and feasibility signs for Moodle program when used for language teaching/learning. This study, therefore, is to answer the problem of whether or not Moodle-based language teaching is worth increasing language learning.

\section{Method \\ Participants}

In the present study, 51 Iranian EFL learners who were the students of two intermediate classes in a private language center in Tehran Province, Iran, were recruited as the participants of the study. One of the classes $(n=26)$ was randomly assigned as the experimental group and the other group $(n=25)$ was assigned as the control group. All the participants were female. 


\section{International Journal of Advanced Multidisciplinary Scientific Research (IJAMSR) ISSN:2581-4281}

Their age range varied from 16 to 21 . The average age of the participant was 18.23 . Although the participants of the two classes were considered as intermediate as reported by the institution supervisor, to ensure the homogeneity of the two groups, the PET was administered to the participants of the two groups. The purpose of the administration of the PET test was to ensure the homogeneity of the students in terms of general language proficiency prior to the treatment. After the administration of the PET, the obtained data were fed to SPSS for the analysis. The result of an independent samples T-test for the mean score of the PET test for both groups revealed that the scores of the two groups were not statistically different in terms of general language proficiency.

\section{Instruments}

\section{Preliminary English Test (PET)}

A PET exam, as an internationally valid proficiency test, was administered in this study as an instrument to measure general language proficiency of the participants of this study prior to the conduction of the treatment. According to the PET Handbook (2004), the test is developed to assess the use of language in real life. PET is based on the communicative approach to learning English while considering the need for accuracy. As for content, the test requires understanding public notices and signs; reading and understanding of short written texts incorporating factual information; understanding of grammar as utilized to express language notions such as time, space, possession, etc. The reliability of the test as estimated by Kudar-Richardson Formula (KR-21) turned out to be 0.87 .

\section{Grammar Test}

To investigate the effect of Moodle-supported instruction on fostering grammar performance, a teacher-made test of grammar served as both pre-test and post-test in the present study. To construct the test, much care was exercised to include grammatical items that were at the level of students. To select appropriate grammatical items for the test, the researcher made use of the other teachers' experience and assistance in constructing appropriate test items. Additionally, various well-established sources, such as Grammar in Use Books, Oxford Grammar Books, and Modern English Books, were employed for the construction of the test items. Before administering the test to the participants, it was piloted to check the psychometric characteristics of the test; that is, the content validity, the appropriateness of the test content, and the test reliability was investigated by two domain experts. The obtained indices for validity and reliability investigation of the teacher-made grammar test indicated that the test enjoyed acceptable degrees of reliability and validity.

\section{Procedure}

Prior to the conduction of the treatment, the teachermade pre-test of grammar was administered during the first session of the course to both the experimental and control groups. For the purpose of the study, the introduction and required information about using Moodle system and Moodle-supported grammar instruction was provided to the students of the experimental group. Both experimental and control group students were required to attend a two-hour regular class twice per week. However, the experimental group students were asked to take part in the assigned online grammar activities for at least three hours per week during the treatment. The students' participation time in the online activities could be examined through the log reports. On the other hand, the students of the control group received regular grammar instruction as covered in the same textbook and the same materials used for the experimental group. The only difference between the two groups was that the experimental group students were required to use Moodle CMS and do the online exercises, while students in the control group students were not provided with Moodle-supported course materials. In addition, PowerPoint slides were regularly posted on Moodle to support the grammar points covered in class for the students of the experimental group. Not only did the slides include the grammatical points covered in the class, but they also provided the hyperlinks to further information, extra activities and quizzes, and YouTube videos for some grammar points. At the end of the experimental intervention, the teacher-made post-test of grammar was administered to the students of both experimental and control groups. 


\section{International Journal of Advanced Multidisciplinary Scientific Research (IJAMSR) ISSN:2581-4281}

\section{Data analyses and results}

In order to measure the grammar performance of the experimental group and that of the control group, a teacher-made grammar test was administered to the students of both groups as pre-test and post-test. The grammar test included the grammar points which were covered and taught by the teacher during the course. In order to analyze the data, the normality of the distribution of the scores was first checked. In order to check this normality assumption, one-sample Kolmogorov-Smirnov (K-S) test was run on both pretest and post-test scores. As it is shown in Table 1., the results of one-sample K-S test indicated that the data was normally distributed; therefore, parametric data analysis methods could be used.

Table 1. One-Sample Kolmogorov-Smirnov Test

\begin{tabular}{|c|c|c|c|}
\hline & & Pre & Post \\
\hline \multicolumn{2}{|l|}{$\mathrm{N}$} & 51 & 51 \\
\hline \multirow[t]{2}{*}{ Normal Parameters ${ }^{\mathrm{a}}$} & Mean & 34.4615 & 39.2308 \\
\hline & Std. Deviation & 9.49605 & $1.05359 \mathrm{E} 1$ \\
\hline \multirow{3}{*}{$\begin{array}{l}\text { Most Extreme } \\
\text { Differences }\end{array}$} & Absolute & .156 & .106 \\
\hline & Positive & .156 & .106 \\
\hline & Negative & -.090 & -.055 \\
\hline \multicolumn{2}{|c|}{ Kolmogorov-Smirnov Z } & 1.123 & .767 \\
\hline \multicolumn{2}{|l|}{ Asymp. Sig. (2-tailed) } & .160 & .598 \\
\hline
\end{tabular}

Then in order to answer the research question, an analysis of covariance (ANCOVA) was run to investigate whether the experimental intervention has been effective or not. According to Hatch and Lazarton (1991), 'ANCOVA makes it possible to control for some variable - perhaps a pre-test score - so that the measurement of the dependent variable is adjusted to take into account these initial differences among the subjects.' In other words, the different scores of the pretest were considered as the covariate and an ANCOVA was run to the data to analyze this difference in the posttest scores between the control and the experimental groups. The results of ANCOVA are presented in Table 2.
Table 2. ANCOVA results for writing performance scores.

\begin{tabular}{|l|l|l|l|l|l|}
\hline Source & $\begin{array}{l}\text { Type III sum } \\
\text { of squares }\end{array}$ & df & $\begin{array}{l}\text { Mean } \\
\text { square }\end{array}$ & $F$ & Sig. \\
\hline $\begin{array}{l}\text { Corrected } \\
\text { model }\end{array}$ & 8435.426 & 2 & 3792.818 & 164.060 & 0.000 \\
\hline Intercept & 18.371 & 1 & 18.289 & .793 & 0.241 \\
\hline $\begin{array}{l}\text { Pre- } \\
\text { Reading }\end{array}$ & 5625.164 & 1 & 6675.564 & 275.241 & 0.000 \\
\hline Group & 357.437 & 1 & 279.537 & 16.023 & 0.000 \\
\hline Error & 874.795 & 40 & 25.630 & & \\
\hline Total & $178,229.000$ & 43 & & & \\
\hline $\begin{array}{l}\text { Corrected } \\
\text { total }\end{array}$ & 8472.431 & 42 & & & \\
\hline
\end{tabular}

As it can be seen from the results, both the pre-test scores of grammar test and the treatment (i.e. Moodle use) had an effect on post-test results. The pre-test scores were taken under control by covariance analysis and it was revealed that the treatment had a statistically significant effect on the post-test results $(F=16.023, p<$ $0.05)$. Since the students in the experimental group improved their grammar performance significantly more than the learners in the control group, it can be concluded that the Moodle-supported grammar instruction has been more effective than adopting only in-class instruction which was the traditional method applied in the control group.

\section{Discussion and Conclusion}

The research question of the present study investigated the effectiveness of Moodle-supported grammar instruction in fostering the EFL students' grammar performance. The results revealed that the students of the experimental group who underwent a blended, Moodle-supported grammar instruction outperformed the control group who were taught traditionally. The main plausible justification may be the more active engagement of the experimental group students in doing the online activities and quizzes provided them via Moodle. As previously discussed, the experimental group students were provided by PowerPoint slides regularly posted on Moodle to supplement the grammar material covered in class. Their further exposure to 


\section{International Journal of Advanced Multidisciplinary Scientific Research (IJAMSR) ISSN:2581-4281}

materials and their more involvement in exercises and online quizzes increased their motivation to learn thereby fostering their grammar performance. The other explanation, of the better performance of the experimental group may be due to more access to fast and immediate peer and teacher feedback. Whenever the quizzes were posted by the Moodle, the students did the exercises and had the opportunity to receive immediate feedback for each response. In addition to receiving immediate feedback for their own responses, the students could also view other comments, discussion, and their peers' replies, encouraging them not only to post replies but also to learn from their peers' and teacher's comments and feedback.

The results of this study chime with the main findings drawn from other similar studies (e.g., Hsieh \& Ji, 2013; Nagata, 1996; Plomteux, 2013; Sahin-K1zıl, 2014), which corroborated the effectiveness of Moodle in enhancing learning grammar. Such studies highlight the enhancement of practitioners' awareness of the effectiveness of Moodle, and other LMSs, in EFL teaching and learning. These studies seem to suggest that Moodle mediation in face-to-face instruction might serve as a catalyst for language learning. However, implementation of Moodle-enhanced instruction might be impeded by teachers' heavy teaching loads, large classes, and lack of required logistic support. More importantly the teachers and practitioners themselves should be willing to adopt this technology. Previous studies (e.g., Gichoya, 2005) have also corroborated that merely having the technological infrastructure in not sufficient for technology to fulfill its promise to higher education if the human resource infrastructure is not addressed. As a result, in addition to providing the students with the necessary infrastructure, both learners and instructors should be trained and get prepared to use new technological devices in general and Moodle in particular. Otherwise, such technologies might remain more a luxury than a utility and a requirement for more effective performance of teachers and students.

The findings of the present study revealed that Moodle provided the students with further scaffolding activities by which the EFL learners could gain a greater level of engagement with grammar points and exercises covered in class. As a remedy to compensate for the constraints of the traditional classroom, the curriculum or existing teaching practice, this study managed to change the structure of the classroom by means of blended learning which involved the integration of a course management system into a traditional, face-to-face classroom. As a matter of fact, the advent of blended learning has been a reaction against the failure of many e-learning environments which lack a face-to-face component (Stracke, 2007). This study was initiated on the assumption that EFL learners need further support and guidance in developing their L2 grammar. Moodle was successful in providing them with 'greater flexibility' in classroom practice, and the teacher provided the students with extra appropriate tools and with opportunities to practice with them. Therefore, it can be argued that application of Moodle, as a course management system was effective in creating this 'greater flexibility'. This finding corroborates the idea of seeking a 'third space' presented by Kramsch (1993) and a 'third culture' by Palfreyman (2003). From this perspective, the course management system acted as a third space which provided greater flexibility in teaching and learning.

From the pedagogical and practical point of view, it is time for the ELT practitioners go beyond teaching grammar traditionally by making the students memorize the rules and exceptions or by providing them with repetitive drills by which the students are not involved in learning the grammar thereby making the grammar learning a tedious burden. The findings of the present study may have this implication that new technological devices such as Moodle e-learning platform may contribute to a deeper and more engaging learning. As far as the Iranian ELT educational system is concerned, the vast majority of foreign language courses in Iran are supported by textbooks and materials accompanied by audio materials such as audio-cassettes, and CDs; Nevertheless, it seems that Iranian students are still unwilling to employ such tools effectively. Therefore, teacher education programs should take it as an imperative to provide the pre-service teachers with both the knowledge and know how of new technological devices and encourage them to employ the devices in their language classes. 


\section{International Journal of Advanced Multidisciplinary Scientific Research (IJAMSR) ISSN:2581-4281}

\section{References}

1. Anohina, A. (2005). Analysis of the terminology used in the field of virtual learning. Educational Technology \& Society, 8 (3), 91-102.

2. Ayan, E. (2015) Moodle as Builder of Motivation and Autonomy in English Courses. Open Journal of Modern Linguistics, 5, 6-20. doi: 10.4236/ojml.2015.51002.

3. Barnett-Queen, T., Blair, R., \& Merrick, M. (2005). Student perspectives of online discussions: strengths and weaknesses. Journal of Technology in Human Services, $23 \quad(3-4), \quad 229-\quad 244$, http://dx.doi.org/10.1300/J017v23n03_05.

4. Bataineh, R. F., \& Mayyas, M. B. (2017). The utility of blended learning in EFL reading and grammar: $A$ case for Moodle. Teaching English with Technology, 7 (3), 35-49 Retrieved 20 September 2017 from http://www.tewtjournal.org/?wpdmact=process \&did $=$ NTAwLmhvdGxpbms.

5. Berns, A., Gonzalez-Pardo, A., \& Camacho, D. (2013). Game-like language learning in 3-D virtual environments. Computers \& Education, 60 (1), 210 220. http://doi.org/10.1016/j.compedu.2012.07.001

6. Blake, R. J. (2008). Brave New Digital Classroom: Technology and Foreign Language Learning. Washington, D.C, USA: Georgetown University Press.

7. Brandl, K. (2005). Are You Ready To "Moodle"? Language Learning \& Technology, 9 (2), 16-23. Retrieved from http://llt.msu.edu/vol9num2/review1/

8. Bruckman, A. (2006). Learning in online communities. In K. R. Sawyer (Ed.), The Cambridge handbook of the learning sciences (pp. 461-472). New York: Cambridge University Press.

9. Burge, E. J. (1994). Learning in computer conferenced contexts: the learners' perspective. Journal of Distance Education, 9 (1), 19-43.

10. Chang, N. (2006). E-discussions as a complement to traditional instruction: did the students like online communication and why? Journal of Early Childhood Teacher Education, 27 (3), 249-264.

11. Cole, J. (2005). Using Moodle: Teaching with the Popular Open Source Course Management System. US: O'Reilly Media, Inc.

12. Compton, L. K. L. (2009). Preparing language teachers to teach language online: a look at skills, roles, and responsibilities. Computer Assisted Language Learning, 22 (1), 73-99. http://doi.org/10.1080/09588220802613831

13. Cross, K. P. (1998). Why learning communities? Why now. About Campus, 3 (3), 4-11.

14. Dziuban, C., Hartman, J., Moskal, P., Sorg, S., \& Truman, B. (2004). Three ALN modalities: An institutional perspective. In J. Bourne \& J.C. Moore (Eds.), Elements of quality online education: Into the mainstream (pp. 127-148). Needham, MA: Sloan-C.
15. Gichoya, D. (2005). Factors affecting the successful implementation of ICT projects in government. Electronic Journal of e-Government, 3 (4), 175-184. Retrieved $18 \quad$ June 2017 from www.ejeg.com/issue/download.html? idArticle $=70$.

16. Hatch, E. and Lazaraton, A. (1991) The Research Manual Design and Statistics for Applied Linguistics. Heinle \& Heinle, Boston.

17. He, K. K. (2004). The New Development of Educational Technology from Blended Learning. EEducation Research, 3, 1-6.

18. Hsieh, P., \& Ji, C. (2013). The effects of computermediated communication by a course management system (Moodle) on English reading achievement and perceptions. Retrieved 18 February 2017 from www.atlantispress.com/php/download_paper.php?id $=8820$.

19. Jarvis, H., \& Krashen, S. (2014). Is CALL Obsolete? Language Acquisition and Language Learning Revisited in a Digital Age. TESL-Ej. Org, 17 (4), 16. Retrieved from http://www.teslej.org/wordpress/issues/volume17/ej68/ej68a1/

20. Jonassen, D. H., Peck, K. L., \& Wilson, B. G. (1999). Learning with technology: A constructivist perspective. Prentice Hall.

21. Knutzen, B., \& Kennedy, D. (2012). The global classroom project: Learning a second language in a virtual environment. Proceedings of the European Conference on E-Government, ECEG, 10 (1), 185 193.

22. Kramsch, C. (1993). Context and Culture in Language Teaching. Oxford University Press, Oxford.

23. Li, J. (2007). Establishing an environment of information courses. Shanghai: Huadong Normal University Publishing Press.

24. Melton, J. (2006).The LMS moodle: a usability evaluation. Language Issues: HCI, 1, 2-24.

25. Nagata, N. (1996). Computer vs. workbook instruction in second language acquisition. CALICO Journal, 14 (1), 53-75.

26. Palfreyman, D. (2003). Introduction: culture and learner autonomy. In: Palfreyman, D., Smith, R.C. (Eds.), Learner Autonomy Across Cultures: Language Education Perspectives. Palgrave Macmillan, Basingstoke, pp. 1-19.

27. Palloff, R. M., \& Pratt, K. (2007). Online learning communities in perspective. In R. Luppicini (Ed.), Online learning communities (pp. 3-15). Charlotte, N.C: IAP.

28. Plomteux, B. (2013). Moodle to the rescue to practice grammar in remediation classes. Proceedings of the Sixth International Conference: ICT for Language Learning (pp. 102-105). Florence, Italy: Libraria Universitaria.

29. Richards, J. C. (2015). The Changing Face of Language Learning: Learning Beyond the Classroom. RELC Journal, 46 (1), 5-22. http://doi.org/10.1177/0033688214561621 
30. Rovai, A. P., \& Jordan, H. M. (2004). Blended learning and sense of community: a comparative analysis with traditional and fully online graduate courses. International Review of Research in Open and Distance Learning, 5 (2). Retrieved from http://www.irrodl.org/index.php/irrodl/article/viewA rticle/192/274.

31. Sahin-Kızll, A. (2014). Blended instruction for EFL learners: Engagement, learning and course satisfaction. JALT CALL Journal, 10 (3), 175-188.

32. Stracke, E. (2007). A road to understanding: a qualitative study into why learners drop out of a blended language learning (BLL) environment. Recall, 19 (1), 57-78.

33. Sun, L. (2014). Investigating the effectiveness of Moodle-based Blended Learning in College English course. International Journal of Information Technology and Management, 13 (1), 83. http://doi.org/10.1504/IJITM.2014.059152

34. Tiene, C. D. (2000). Online discussions: a survey of advantages and disadvantages compared to face-toface discussions. Journal of Educational Multimedia and Hypermedia, 9 (4), 371-384.

35. Tsai, Y.-R. (2014). Applying the Technology Acceptance Model (TAM) to explore the effects of a Course Management System (CMS) -Assisted EFL writing instruction. CALICO Journal, 32, 153-172.

36. Tsai, Y., \& Talley, P. (2014). The effect of a course management system (CMS)-supported strategy instruction on EFL reading comprehension and strategy use. Computer Assisted Language Learning, 27 (5), 422-438.

37. Whipp, J. L. (2003). Scaffolding critical reflection in online discussions: helping prospective teachers think deeply about field experiences in urban schools. Journal of Teacher Education, 54(4), 321334.

38. White, C. (2007). Innovation and identity in distance language learning and teaching. Innovation in Language Learning and Teaching, 1 (1), 97-110. 